\title{
Classifying theories of welfare
}

\author{
Christopher Woodard
}

Published online: 3 July 2012

(C) The Author(s) 2012. This article is published with open access at Springerlink.com

\begin{abstract}
This paper argues that we should replace the common classification of theories of welfare into the categories of hedonism, desire theories, and objective list theories. The tripartite classification is objectionable because it is unduly narrow and it is confusing: it excludes theories of welfare that are worthy of discussion, and it obscures important distinctions. In its place, the paper proposes two independent classifications corresponding to a distinction emphasised by Roger Crisp: a fourcategory classification of enumerative theories (about which items constitute welfare), and a four-category classification of explanatory theories (about why these items constitute welfare).
\end{abstract}

Keywords Welfare $\cdot$ Typology Explanatory question $\cdot$ Enumerative question

Making progress in the philosophy of welfare is extremely hard, and we should not place unnecessary obstacles in the way. In this paper, I claim that the standard tripartite classification of theories of welfare-into hedonist theories, desire theories, and objective list theories - is just such an obstacle. This classification encourages confusion and narrow-mindedness. I propose a different classification that does not suffer these faults. I do not claim that, if only philosophers adopted this alternative, we would make much more progress. But I do claim that the traditional classification is a needless obstacle to progress. Replacing it will not do any harm, and may well do some good.

There are several different things one might call a 'theory of welfare'. One such thing is a theory about the relationship between the concept of welfare and other important concepts, such as reason or goodness. Though this is an important kind of

C. Woodard ( $\square)$

Department of Philosophy, University of Nottingham, University Park, Nottingham NG7 2RD, UK

e-mail: christopher.woodard@nottingham.ac.uk 
theory about welfare, it is not the sort of theory at issue here. For the purposes of this paper, I will assume a standard view about the relationship between welfare and other ethical concepts, which is that the concept of subject $S$ 's welfare is the concept of what is non-instrumentally good for $S$ (Crisp 2006, p. 100; Feldman 2004, pp. 8-14; cf. Darwall 2002). The 'theories of welfare' under discussion in this paper are different views about which things are non-instrumentally good for someone, and why. Hedonism, desire theories, and objective list theories are usually understood as candidate answers to these questions. For simplicity, I will refer to any philosophical claim, position, or view about these matters, no matter how well developed, as a 'theory of welfare'. I will not be concerned with the truth of any theory of welfare, but only with how to classify them in a helpful way.

My thesis is that philosophical discussion of welfare is likely to be hindered rather than served by the tripartite classification. In Sect. 1 I shall explain what I think is wrong with it, and in Sects. 2 and 3 I shall propose a new way to classify theories of welfare.

My central claims are modest and non-comparative. One way of proceeding would be first to establish the theoretical values that we should use to evaluate classificatory schemes in general, and then to claim that we should reject the tripartite classification because it is less good, in these respects, than the new classification proposed here. But the first part of this method is extremely ambitious, and I do not attempt it. Instead I make two simpler claims in succession. First I claim that the tripartite scheme has two faults that I assume are clear disqualifiers of possible classificatory schemes: it is unduly narrow and it obscures important distinctions. These faults make it an obstacle to progress in this area, and provide a non-comparative reason for rejecting it. I then propose a different way of classifying theories of welfare. Whatever its merits all things considered, this classification does not have the defects of the tripartite scheme. So it is at least not disqualified on those grounds.

\section{The tripartite classification}

The tripartite classification is common but not universal in contemporary philosophical discussions of welfare. For example, it is used in Parfit's, Kagan's, and Crisp's influential discussions (Parfit 1987, pp. 493-502; Kagan 1998, pp. 29-41; Crisp 2006, p. 98; 2008; see also Scanlon 1998, p. 113; Sumner 1996, Chaps. 3-5). Some other commentators adapt the tripartite classification, adding further categories. Thus, for example, Haybron distinguishes the following main philosophical views about welfare: hedonism; desire theories; list theories; authentic happiness theories; and nature-fulfilment theories (2008, pp. 33-36). ${ }^{1}$

It is possible to utilise the tripartite classification, or some cousin of it, whilst holding any of a wide range of different background views about its usefulness, exhaustiveness, and so on. So I should be clear that, in criticising the tripartite

\footnotetext{
${ }^{1}$ I have listed Haybron's categories in a different order than he does. See also Feldman (2004, pp. 15-20), Heathwood (2010), Carson (2000).
} 
classification, I do not take myself to be criticising any of these authors. Many or all of them may have similar, or more stringent, misgivings about it. ${ }^{2}$ I mean only to claim that the classification itself is unsatisfactory, and then to propose a different way of classifying theories of welfare that does not suffer the same problems.

Arguing about the merits of one or other typology obviously raises the issue of what we should take to be the virtues or vices of typologies of philosophical views or theories. No doubt there is room for substantive philosophical disagreement about this. It would be an interesting and important exercise to try to clarify the considerations favouring one or other method of classifying philosophical views in general. But I do not attempt this ambitious exercise here. Instead, I merely assume that the following two features are together sufficient to disqualify a possible classificatory scheme. First, the scheme is unduly narrow, in the sense that it encourages us to overlook views about the issue in question that are worthy of discussion. Second, the scheme is confusing, in the sense that it encourages us to conflate distinct issues. I take it that these are serious faults. It is hard to see why one should accept a classificatory scheme that suffers from just one of them; but in any case I assume that we should not accept any scheme that suffers from both. I shall now claim that the tripartite classification of theories of welfare does suffer from both of these defects.

Consider the first point. An initial criticism of the tripartite classification might be that it excludes interesting views such as those that Haybron adds to his list. For example, Sumner's view that welfare consists in authentic happiness does not seem to fit any of the three categories, yet seems very interesting and worthy of discussion. Authentic happiness, as Sumner defines it, cannot properly be assimilated either to any form of pleasure or to any form of desire-satisfaction. Yet it seems strained to place Sumner's view into the category of objective list theories, since he is at pains to criticise objective theories of welfare (1996, Chaps. 2-3).

This seems to be a fair criticism. Supposing that this classification is meant to be exhaustive, we must either find a place for Sumner's view in one of the three categories, or deny that it is interesting or otherwise worthy of inclusion, or amend the tripartite classification. Neither of the first two options is very appealing. The same goes for other theories apparently excluded by the tripartite classification. For example, consider welfare nihilism. According to this view, there are no constituents of welfare, since nothing is non-instrumentally good for anyone. This seems to be a coherent view, and certainly it is worthy of discussion. So Haybron seems right to modify the tripartite classification, adding further categories to allow for other views, including Sumner's.

Defenders of the tripartite classification might make a number of objections at this point. They might, first, deny that the classification is supposed to apply to all worthwhile philosophical theories of welfare. This may well be true of many particular uses of the classification, but it is not a powerful defence of the classification itself. The fact that one can make some use of a non-exhaustive typology hardly goes to show that we should not prefer typologies to be exhaustive.

\footnotetext{
${ }^{2}$ Crisp (2008) expresses some doubts about it, for example.
} 
Nor is it particular hard for a typology to be exhaustive: it just has to have an appropriately defined residual category.

A second possible objection would be to claim that the tripartite classification contains just such a residual category: the category of 'objective list theories'. This response has some plausibility. The category of objective list theories can be treated to some extent as a residual category, containing views that perhaps share little in common other than not being versions of hedonism or the desire theory. For example, for some purposes one might want to classify welfare nihilism as a limiting case of an objective list theory, in which the list contains no items. One might assume at first that this should not be thought an 'objective' list theory: there would be no items, therefore no objective items, on the list; and the theory would not be committed to the existence of objective values. But there is perhaps a sense in which welfare nihilism is an objective theory: it claims that the truth about welfare is independent of whatever people happen to care about or in any other way subjectively endorse. Perhaps this is the sense of 'objective' that is supposed to unite the members of the third category. Whether or not that is so, though, we cannot really expect all of the interesting alternatives to hedonism and the desire theory to be 'objective' theories in this sense. ${ }^{3}$ It seems unlikely that Sumner's view, for example, is objective in the way that is meant when theories of welfare are called 'objective list views'.

For these reasons it seems that the tripartite classification as it is cannot plausibly claim to be exhaustive. One must either accept that it excludes some interesting views, or make the significant change of dropping 'objective' from the specification of the third category, thereby enabling it to be a proper residual category. We could call theories of this third type 'other list theories', for example. This would indeed be a significant change, since current uses of the tripartite classification sometimes take this 'objective' to mark a significant defining feature of the category. ${ }^{4}$

So, the tripartite classification is unduly narrow. Still, one might think that a fairly simple change is in order, and that a modified three-category typology of theories of welfare would be exhaustive and would serve well. We might argue over whether further subdivisions in the residual category would be helpful, but these disputes seem to rely on judgement calls. It would not be obviously unreasonable to prefer fewer to more categories in a typology of this sort once room has been found for all of the interesting views.

However, we have another powerful reason for seeking a more radical change to the tripartite classification. This is that it encourages us to conflate different issues. In particular, it obscures two important distinctions.

First, it obscures the distinction between what Crisp has called the enumerative and the explanatory questions about welfare (2006, pp. 102-103). The enumerative question is this: what are the constituents of (some subject's) welfare? Any answer

\footnotetext{
3 Perhaps this explains why Haybron $(2008$, pp. 34, 36) refers to 'list views' rather than 'objective list views'. However, any theory that answers the enumerative question (on which, see below) might be called a 'list view'.

${ }^{4}$ For example, Kagan contrasts hedonism and desire theories with 'objective theories', which he defines as 'theories that hold that being well off is a matter of having certain goods in one's life, goods that are simply worth having, objectively speaking' (1998, p. 39).
} 
to this question must be a list of some sort, so every enumerative theory of welfare is a list theory. The explanatory question is different: in virtue of what is any given item supposed to be a constituent of (some subject's) welfare? Note that different answers to this question might be proposed for any particular item enumerated. For example, suppose we agree that pleasure is a constituent of welfare. In virtue of what is it a constituent? One possible answer is that it is a constituent of welfare because of its pleasurableness. But this explanation is not mandatory for every enumerative hedonist. One could claim that pleasure is a constituent of welfare because it satisfies the subject's desires, or because it is objectively good, or because Dionysus made it so, for example.

The standard tripartite classification makes it very hard to keep Crisp's important distinction clearly in view. Admittedly, the classification is not outright incompatible with Crisp's distinction. But if we keep Crisp's distinction in mind, the tripartite classification just looks baffling. Why contrast 'hedonism' (on the face of it, a purely enumerative view) with 'objective list theories' (on the face of it, a category defined in part or whole by an answer to the explanatory question)? Why think that, if one's answer to the enumerative question is not 'pleasure' or 'satisfaction of desires' (or some combination thereof), one is thereby committed to an 'objective' answer to the explanatory question? Worse, why think that if one's answer to the enumerative question is 'pleasure' or 'satisfaction of desires' (or some combination thereof), one is thereby committed to rejecting an 'objective' answer to the explanatory question?

Even the modified tripartite classification, in which the third category is 'other list theories', makes it hard to focus on the difference between explanatory and enumerative issues. This is because it is not clear which of these questions desire theories of welfare are supposed to answer. Recently, Guy Fletcher has argued that desire theories must be understood as explanatory theories of welfare, not as enumerative theories. They claim that the things that constitute Smith's welfarenamely, the things that satisfy her desires-do so because they satisfy her desires. Adding an enumerative claim to the effect that the constituents of her welfare are the things that satisfy her desires is redundant and uninformative (Fletcher, forthcoming). If Fletcher is right, the modified tripartite classification crossclassifies theories. It sorts theories into three categories, two of which ('hedonism' and 'other list') are defined by reference to the enumerative issue, and one of which ('desire theories') is defined by reference to the explanatory issue.

Fletcher might be wrong that the desire theory cannot be understood as an enumerative theory. Possibly one could think of some desire theories as enumerative theories. 'Whatever Smith desires' is an economical (though admittedly not, by itself, very informative) enumeration of the particular things that Smith desires. This enumeration could be paired with a quite different explanatory theory, in which the explanation of why these things constitute Smith's welfare is, say, that Smith fulfils her nature as an autonomous agent by having desires and satisfying them. The explanatory theory could claim that fulfilling one's nature as an autonomous agent is objectively valuable in some way. Then we would have the combination of an 'objective' explanatory theory and a version of the desire theory as an enumerative theory. 
However, Fletcher is surely right that it makes sense to think of many desire theories as explanatory rather than enumerative. So, even if some desire theories are enumerative, the tripartite classification still cross-classifies, and so makes it harder to keep Crisp's distinction in view.

What is more, the tripartite classification obscures another important distinction. Consider the difference between hedonist and desire theories of welfare, where both are understood as enumerative theories. What distinguishes them? One possible answer is that the main difference between them is that one (hedonism) is a 'mental state' view, since the items it enumerates are mental states, while the other (the desire view) is a 'world state' view, since the items it enumerates are states of the world (Griffin 1986, Chap. 1).

This is, no doubt, an important difference between most versions of these views. ${ }^{5}$ However, there may be other important differences. Though one view about the nature of pleasure is that it is a mental state that is desired in some way, this is controversial. It is a form of 'externalism', since it claims that what pleasures share in common is some relation to a positive attitude of some kind. Other externalist views are possible, according to which the relation is to some attitude other than desire. 'Internalist' views are also possible, according to which pleasures are united by the way they feel (Brandt 1979, pp. 40-41; Sumner 1996, pp. 87-94; Crisp 2006, pp. 103-111; Feldman 1997). Our classification of theories of welfare ought not to rule out any of these views. So, it should leave room for hedonist theories according to which pleasure involves some positive attitude other than desire, and for hedonist theories according to which pleasure involves a positive feeling of some kind. We could think of these other attitudes, or the positive feeling, as possible kinds of subjective endorsement. ${ }^{6}$ These possible kinds of subjective endorsement are independent of desire. For simplicity, I will say that they are all examples of the idea of liking something. To like something is to endorse it in some way that is conceptually independent of desiring it. ${ }^{7}$

If that is right, we should not run together the following two possible distinctions between hedonism and desire theories. One issue is whether a theory of welfare enumerates mental states or world states (or both). A quite different issue is whether it enumerates things the subject desires or things she likes. On the face of it, there are at least four possible combinations of answers to these questions. In encouraging us to run these two distinctions together the tripartite classification once again hinders philosophical discussion of welfare.

\footnotetext{
${ }^{5}$ But not all: Heathwood (2006) claims that the most plausible version of hedonism is identical to the most plausible version of the desire view.

${ }^{6}$ For this to be compatible with internalism about pleasure, we must allow that when something feels good there is a sense in which the subject 'endorses' it-despite it not being the case that any other attitude towards the feeling need be involved.

7 Crisp's discussion of enjoyment postulates a kind of liking in the sense I have described. For example, he writes, 'It seems to me there can be enjoyment without desire. Imagine an ascetic who very strongly wishes that the enjoyment he is experiencing from being near to someone sexually attractive to him would stop. I fail to see why this must be construed as a case of conflict of desires' (2006, p. 107 n. 38). Haybron's discussion of happiness as 'psychic affirmation' of one's life is a different example of the concept of desire-independent subjective endorsement (2008, Chap. 7).
} 
We should reject the tripartite classification even in its modified form. It is unduly narrow, and it makes it hard to keep important distinctions clearly in view. We should look for a way of classifying theories of welfare that does not have these defects. In what follows I suggest one such way. It seeks to entrench Crisp's distinction through the inelegant but apparently inescapable method of proposing two separate classifications: one for enumerative theories and one for explanatory theories. It also seeks to highlight the possibility of non-standard and hybrid theories. Other, better, typologies may well be possible. But the main point is that we should not continue to labour under the unnecessary burdens imposed by the tripartite classification.

\section{A new typology of enumerative theories}

First, then, consider the range of possible answers to the enumerative question. One important answer, as we have already noted, is that nothing is non-instrumentally good for anyone (which seems to imply that nothing is good for anyone, full stop). Welfare nihilism is an interesting enumerative theory, and it is certainly worthy of discussion. So it should be included in a satisfactory typology of enumerative theories. But let us consider the non-nihilistic alternatives. One basic question is whether there is any informative, true, general answer to the enumerative question. We are all familiar with the fact that, when we specify concrete instrumental goods, different things appear to be good for different people. Broccoli is good for some, but bad for those who are allergic to it. We tend to assume that, when we specify noninstrumental goods, we must simultaneously shift to more abstract specifications, such as 'pleasure' or 'friendship'. We further tend to assume that, in giving abstract specifications of noninstrumental goods, we will be able to answer the enumerative question in a way that is informative, general, and true.

But these assumptions could be false. Why must noninstrumental goods be specified in abstract terms? It could be that we assume they must because we tend to run-together the enumerative and explanatory questions. That might explain why, for example, we would be more inclined to suggest that 'friendship' is a candidate constituent of welfare than that particular friendships are. Yet, on the face of it, it seems more natural to say that particular friendships are good for me, than that friendship is; and when we distinguish clearly between the enumerative and explanatory tasks, we may be more inclined to specify concrete items rather than abstract ones. ${ }^{8}$ Second, the tendency to specify the constituents of welfare in abstract terms may obscure the possibility of welfare variabilism: the view that, when specified informatively, the constituents of welfare are different for different individuals (Fletcher 2008, Chap. 6; 2009). ${ }^{9}$ Those who would apply the concept of welfare to non-human animals might well accept that the constituents of welfare for

\footnotetext{
${ }^{8}$ Abstract enumerations may be more economical, however. Rather than saying that each of my particular friendships is non-instrumentally good for me, we can say simply that friendship is.

9 Bailey (1997, p. 6) notes briefly that '[it] may... be the case that there are no goods that are identifiably goods for all actually existing persons, and there may be goods that are goods for only one person'.
} 
members of one species are different from the constituents of welfare for members of another. Should we assume that such variation could not occur within species? If not, should we assume that it could not occur within the species Homo sapiens? Perhaps it could not: but that seems a substantive thesis, and worth debating.

So we should leave room in a classification of enumerative theories for nihilism and variabilism. How should we divide the class of invariabilist (and non-nihilist) enumerative views? There are, no doubt, many ways of doing this. Some of these will suit some purposes better than they suit others. For example, it might well be worthwhile dividing enumerative views according to their metaphysical commitments: in particular, the bearers of value they posit. Though that approach may be worthwhile, I will propose something more familiar to ethical discussions. I propose that we divide invariabilist theories according to whether they accept or reject two independent theses, which I will call the experience requirement and the desire requirement.

A theory accepts the experience requirement just in case it claims that, for any subject $S$, the only constituents of $S$ 's welfare are $S$ 's experiences (Griffin 1986, pp. 13, 16-19; Scanlon 1993, pp. 186-187; 1996, pp. 127-128). ${ }^{10}$ According to such theories, if some fact about my life does not affect my experience it cannot affect my welfare. Which experiences constitute welfare is of course a further matter, over which theories accepting the experience requirement may differ. And, of course, an enumerative theory may fail to endorse the experience requirement yet still include certain experiences as constituents of welfare. So the class of theories that do not impose the experience requirement is not the same as the class of theories that altogether ignore experiences.

The second distinction is between those theories that do and those that do not accept the desire requirement. A theory accepts the desire requirement just in case it claims that, for any subject $S$, the only constituents of $S$ 's welfare are satisfactions of some set of desires that is appropriately related to $S$ 's desires. ${ }^{11}$ This condition can be interpreted in importantly different ways, according to how some key terms are understood. First, we could understand 'satisfaction of a desire' in the standard way, according to which $S$ 's desire for $X$ is satisfied if and only if $X$ obtains. This has the effect of making any theory that accepts the desire requirement (understood in this way) a 'world state theory'. ${ }^{12}$ Alternatively, we could understand 'satisfaction of a desire' as subjective satisfaction, according to which $S$ 's desire for $X$ is satisfied if and only if $S$ believes that $X$ obtains (Heathwood 2006, pp. 547-551). This has the effect of making any theory that accepts the desire requirement (understood in this way) a 'mental state theory' (Griffin 1986, pp. 7-8; Heathwood 2006, p. 550). Since it is often thought that mental state theories are at a significant disadvantage due to

\footnotetext{
${ }^{10}$ There are of course difficulties in specifying the experience requirement precisely, since it is not straightforward to specify what is involved in something's being an experience. Fortunately we can leave these difficulties aside here.

11 We can generate different versions of the desire requirement by understanding 'desire' more or less broadly. Broader versions include some pro-attitudes that are not ordinarily called 'desires', such as wantings or endorsements. I am grateful to an anonymous reviewer for discussion of this point.

12 This assumes that the desire is for a state of the world to obtain. See Griffin (1986, pp. 7-17).
} 
Experience Machine worries, this is of course an important distinction (Nozick 1974, pp. 42-45). ${ }^{13}$

The second important term in the specification of the desire requirement concerns the precise set of desires whose satisfaction is said to constitute welfare. My formulation was: some set of desires that is appropriately related to the subject's desires. This clearly leaves room for a great variety of significantly different views.

The simplest view is the actual desire view, according to which the welfare of subject $S$ at time $t$ is constituted by satisfaction of $S$ 's actual desires at time $t$. But for familiar reasons, those who propose desire theories typically do not adopt this view. Instead they tend to claim that the relevant set of desires is related in some more complex way to the subject's actual desires. One important refinement is the distinction between intrinsic and extrinsic desires. To have an intrinsic desire for something is to desire it for its own sake, whereas to have an extrinsic desire for something is to desire it for the sake of something else (for example, as a means to that thing). On the face of it, the satisfaction of intrinsic desires is what matters for welfare (Feldman 2010, pp. 59-60; Heathwood 2006, pp. 540-541). Another possible refinement seeks to adjust for poor information or understanding. More or less expansive accounts of what counts as poverty of information or understanding will then lead to markedly different forms of desire theory (Griffin 1986, pp. 10-17). Third, the theory may discriminate among desires according to their subject matter. One such possibility is to distinguish between 'local' and 'global' desires: global desires are about part or all of one's life considered as a whole, whereas local desires are not (Parfit 1987, pp. 496-499). Another possibility is to seek to exclude desires that seem to have little to do with the subject's welfare. As Scanlon puts it, 'a person can in principle have preferences about anything whatever-about the number of moons the planet Uranus has, about the colour of Frank Sinatra's eyes, or about the sexual mores of people whom they will never see' (Scanlon 1993, p. 186). ${ }^{14}$ To answer such worries, desire theories may seek to exclude desires that are not about the subject's own life.

On most interpretations, the experience requirement is independent of the desire requirement. If 'satisfaction of desire' is understood as subjective satisfaction, and we assume that to believe that $X$ obtains is to have a certain sort of experience, then it follows that any theory of welfare that accepts the desire requirement must also accept the experience requirement. Otherwise, the two requirements are independent of each other.

We can imagine a kind of theory according to which the constituents of welfare are a set of desired experiences, and we can contrast this with a second kind of theory according to which the constituents of welfare are a set of experiences that need not be desired. We can contrast both of these with a third kind of theory, according to which the constituents of welfare must be desired but need not be experienced, and a fourth theory according to which the constituents need not be desired or experienced. In sum, the two requirements can be combined to yield the possibilities shown in Table 1.

\footnotetext{
${ }^{13}$ Heathwood (2006) and Crisp (2006) are notable recent attempts to defend mental state theories.

${ }^{14}$ See also Parfit (1987, pp. 494-495); Griffin (1986, pp. 16-17, 21-23).
} 
Table 1 Possible combinations of the experience and desire requirements

\begin{tabular}{lll}
\hline & $\begin{array}{l}\text { Accepts desire } \\
\text { requirement }\end{array}$ & $\begin{array}{l}\text { Does not accept } \\
\text { desire requirement }\end{array}$ \\
\hline $\begin{array}{l}\text { Accepts experience } \\
\text { requirement }\end{array}$ & 1 & 2 \\
$\begin{array}{l}\text { Does not accept experience } \\
\text { requirement }\end{array}$ & 3 & 4 \\
\hline
\end{tabular}

Each of these four categories contains considerable internal diversity, only some of which we have noted already in relation to the interpretation of each requirement. For example, hedonist views occupy Cells 1 or 2, according to the theories of the nature of pleasure they employ. Desire-based externalist theories of pleasure yield forms of hedonism that accept both the desire and experience requirements, and so fall in Cell 1. But these cells also contain views that, though focused on experiences, are not hedonist. For example, welfare eudaimonism claims that welfare consists in happiness, which may or may not consist in pleasurable experience. ${ }^{15}$

Note also that accepting the experience requirement by itself does not make a theory a 'mental state' theory, if by that is meant a theory that treats all phenomenologically indistinguishable mental states alike. Accepting the experience requirement is, after all, compatible with accepting additional requirements. ${ }^{16}$ For example, veridical hedonism claims that only veridical pleasures contribute to welfare. For those attracted to hedonism but worried by Nozick's Experience Machine, it might be an appealing theory. ${ }^{17}$ (Whether veridical hedonism can be supported by an appealing explanatory theory is a good question, though not a typological one. The present point is that it is a possible form of hedonism, and that affirming the experience requirement does not amount to endorsing pure mentalstatism.)

Standard forms of 'desire theory' occupy Cell 3, since they reject the experience requirement. But we have already noted that these theories can differ greatly from each other according to the precise set of desires they count as relevant. In addition, we noted that interpreting 'satisfaction' as subjective satisfaction might produce a view in Cell 1. A different way to produce a view in Cell 1 is to restrict the relevant set of desires to those that concern the subject's experiences. The constituents of welfare would then be a set of desired experiences (this may be equivalent to some forms of externalist hedonism). Further, two important kinds of hybrid view occupy Cell 3. According to the first, two-way hybrid, welfare consists in getting things one

\footnotetext{
15 Sumner (1996, pp. 138-183) develops a theory of welfare as authentic happiness. Haybron (2008) develops an 'emotional state' account of happiness, and argues that happiness is central to, though not identical with, welfare. Scanlon (1993, p. 186) calls any theory that accepts the experience requirement 'hedonism', but this very broad usage is needlessly revisionist. I am grateful to Guy Fletcher for discussion of this point.

16 One important example of such a theory is the idea that welfare consists of enjoying the good. See Kagan (2009).

17 Veridical hedonism is of course a 'mental state' theory in the following different but important sense: the items it enumerates are all mental states. But note that this is not the sense of 'mental state theory' according to which all such theories are subject to Experience Machine worries.
} 
desires and liking them. This view trades on the supposition mentioned in Sect. 1 above that 'desiring' and 'liking' involve two different kinds of subjective endorsement. But though the two-way hybrid appeals to the 'liking' kind of endorsement associated with some forms of hedonism, it claims that the constituents of welfare are the things that satisfy desires (and which are liked), and so it does not accept the experience requirement. Similarly, according to the three-way hybrid, welfare consists in getting things of objective value that one desires and likes. ${ }^{18}$

Finally, Cell 4 of course contains enormous diversity. It is a residual class, and so contains a very wide range of views. Views in this category may be monist or pluralist, and they may of course include satisfaction of desire, or certain experiences, or both, in their enumerations, but they nevertheless reject both requirements. An important kind of hybrid, disjunctive hybrid views, fit into this category. According to such views, an item must be an experience of a certain kind, or the satisfaction of a desire (or, perhaps, something else, such as objectively valuable), to be a constituent of welfare. Such hybrid views deny both the experience and desire requirements, despite making central use of the concepts of experience and desire (Hawkins 2010).

If we classify enumerative theories according to their endorsement or otherwise of the two requirements I have discussed, we get the classification shown in Table 2 (the theories listed are for illustration: the lists are not supposed to be exhaustive).

There is a limited resemblance between this classification and the tripartite classification discussed in Sect. 1. In particular, hedonist theories and desire theories both feature in my proposed classification. For certain purposes, we might wish to focus attention on these two kinds of theory, and perhaps we might wish to consider them alongside a category featuring the views that fit the classification 'objective list theories'. We can still do this if we wish. But my classification has a number of advantages over the tripartite classification. First, it raises the profile of other possible enumerative views, such as the different kinds of hybrid view, variabilism, or nihilism. It also classifies views strictly according to their answers to the enumerative question, thus helping us to respect Crisp's distinction. It does nothing to obscure the possibility of distinguishing different kinds of subjective endorsement. Finally, it encourages discussion of theses - in particular, the two requirements used to organise the views - rather than of traditions — such as 'hedonism' or 'desire theory'.

\section{A new typology of explanatory theories}

Let us turn now to explanatory theories. These theories attempt to explain why some particular enumerated items constitute (some subject's) welfare. The most salient distinction amongst possible explanatory theories is between 'subjective' and 'objective' theories. These terms are of course treacherous-especially here, where meta-ethical, ethical, and political intuitions are apt to collide. One important point

\footnotetext{
18 A different kind of hybrid combines objective value with just one kind of subjective endorsement. For example, see Heathwood (2010, p. 652).
} 
Table 2 Proposed classification of enumerative theories

\begin{tabular}{lll}
\hline & Accepts desire requirement & Does not accept desire requirement \\
\hline $\begin{array}{l}\text { Accepts } \\
\text { experience } \\
\text { requirement }\end{array}$ & $\begin{array}{c}\text { Desire-based externalist forms of hedonism; } \\
\text { non-hedonist theories, such as some forms } \\
\text { of eudaimonism; subjective satisfaction } \\
\text { desire theories; welfare nihilism }\end{array}$ & $\begin{array}{c}\text { Internalist forms of hedonism; non- } \\
\text { hedonist theories, such as some } \\
\text { forms of eudaimonism }\end{array}$ \\
$\begin{array}{l}\text { Does not accept } \\
\text { experience } \\
\text { requirement }\end{array}$ & $\begin{array}{c}\text { Standard desire theories; two-way hybrid; } \\
\text { three-way hybrid }\end{array}$ & $\begin{array}{l}\text { Other invariabilist theories, including } \\
\text { disjunctive hybrid theories; welfare } \\
\text { variabilism }\end{array}$ \\
\hline
\end{tabular}

\footnotetext{
${ }^{a}$ Strictly, welfare nihilists can accept both the experience and desire requirements. I am grateful to Carrie Ichikawa Jenkins for this point
}

is that we should be careful not to slide back over Crisp's distinction. A philosophical theory of welfare could be 'subjective' in the sense that its answer to the enumerative question lists some subjective feature of lives such as pleasurable experiences, even though it endorses an objective answer to the explanatory question. In the sense with which we will be concerned, though, the distinction between subjective and objective theories applies only to different possible answers to the explanatory question.

Sumner has a careful discussion of the appropriate sense of 'subjective' in relation to welfare. He concludes that we should reserve the term 'subjective' for those theories according to which nothing can constitute a person's welfare unless she has some appropriate positive attitude towards it. Any other theory he deems 'objective', so that the two categories are jointly exhaustive (Sumner 1996, p. 38). ${ }^{19}$

Though it is helpful, I think we should depart from Sumner's way of drawing this distinction in two respects. First, we should define the category of subjective theories more narrowly. I assume that a large part of the interest in explanatory subjectivism has to do with worries about the ontological and epistemological commitments of objective theories of value. If so, Sumner's category is certainly too broad, since it includes hybrid explanatory theories according to which something can be a final good for a person only if she has some appropriate positive attitude towards it and it merits that attitude by being objectively valuable. Such views could have commitments that most anti-objectivists would find extravagant. So Sumner's classification does not serve one of our main interests in distinguishing 'subjective' and 'objective' theories.

The problem is that Sumner makes the distinguishing feature of subjectivism the idea merely that appropriate positive attitudes are necessary for something's being a constituent of welfare. As we have just seen, this is compatible with the idea that objective value is also necessary for something's being a constituent of welfare. We could exclude that possibility by stipulating that a theory is subjective only if it claims that appropriate positive attitudes are both necessary and sufficient for something's being a constituent of welfare. Sumner considers this, but rejects it on the grounds that '[j]ust as subjective analyses of colour are likely to regard it as the product of an

\footnotetext{
19 'Attitude' is Sumner's general term for any kind of valenced mental state, such as 'wanting, or liking, or enjoying, or approving' (1996, p. 37).
} 
interaction between a perceiving subject and a perceived object, subjective analyses of welfare are also likely to be relational or dispositional' (1996, p. 38). I take it that this means that we should allow for subjective theories, like standard forms of desire theory, that account for welfare partly in terms of states of the external world (so that it is possible to distinguish between cases in which someone's desire is really satisfied and cases in which she erroneously believes it to be satisfied).

Certainly it is important to allow that some subjective theories of welfare will track this distinction or in other ways refer to states of the external world. The 'world-involving' nature of standard forms of desire theory is much emphasised in the literature on welfare. And we should define explanatory subjectivism so that it is compatible with desire theories. However, this does not speak against defining subjective theories as those that answer the explanatory question by reference only to the subject's attitudes. To think otherwise is to confuse enumerative issues with explanatory ones. The distinction between genuinely satisfied desires, and desires erroneously believed to be satisfied, appears to fall on the enumerative side of Crisp's distinction. In the first place at least it is a matter of which things contribute to welfare, not of what explains why these things contribute to welfare. One can hold that genuine desire satisfaction contributes to welfare while mere subjective satisfaction does not, yet still seek to explain why desire satisfaction contributes to welfare entirely in terms of the subject's attitudes.

Thus we should define a theory as subjective just in case it answers the explanatory question entirely in terms of the subject's attitudes. Such theories claim that the subject's attitudes alone explain why certain things are non-instrumentally good for her. They can be combined with enumerative claims that refer to states of the external world. But they cannot appeal to anything other than the subject's attitudes in answering the explanatory question. This is why hybrid theories-which answer the explanatory question in terms of the subject's attitudes but also refer to objective values - do not count as subjective theories on my proposal.

The second departure from Sumner's way of drawing the distinction is to treat objective views as merely a subset of possible non-subjective views. Consider a view according to which the answer to the explanatory question has to do exclusively with facts about biological function. ${ }^{20}$ Such a view is not subjective, since it does not answer the explanatory question in terms of the subject's attitudes. But it seems not to be objective either, at least if the point of distinguishing subjective views from objective ones is largely to do with controversies about the existence of objective values. The sort of view I have in mind makes no reference to values. So I propose that we distinguish objective views from naturalist ones. A theory is objective just in case it answers the explanatory question by appeal to objective values, even if it appeals to other considerations as well. Thus, the hybrid views I mentioned earlier are objective on this usage. A theory is naturalist just in case it answers the explanatory question without appeal to objective values and not entirely in terms of the subject's attitudes. ${ }^{21}$ Theories that appeal to naturalist

\footnotetext{
${ }^{20}$ Foot (2001) may be an example of this sort of view.

21 Of course it may be difficult to decide whether some particular consideration counts as an objective value. I leave that issue aside here.
} 
considerations such as facts about biological function and also to objective values are a second kind of hybrid. As with the other kind of hybrid, my classification includes these amongst objective theories.

So far we have three categories of explanatory theory: subjective, objective, and naturalist. We should add a fourth: no-answer theories, according to which there is no true, general, and informative answer to the explanatory question. Scanlon seems inclined to endorse such a view when he writes that the most plausible kind of 'substantive good' theory:

... claims that certain diverse goods make a life better, and it will be prepared to defend this claim by offering reasons (possibly different in each case) about why these things are desirable. But it may offer no unified account of what makes things good. It seems to me unlikely that there is any such account to be had, since it is unlikely that there are any good-making properties which are common to all good things. If this is correct, then there will be no general theory of goodness in between, on the one hand, a purely formal analysis of 'good' such as 'answers to certain interests' or 'has the properties it is rational to want in a thing of that kind' and, on the other hand, diverse arguments about why various properties of particular objects make those objects good. (Scanlon 1993, p. 191; see also Scanlon 1998, pp. 125-126.)

No-answer views claim that it is a mistake to expect such an answer, just as some intuitionists claim that it is a mistake to expect a true and informative answer to the question of what makes it the case that we have the duties we have. Such views seem coherent and worthy of discussion. Thus we should include them in our typology of possible answers to the explanatory question.

Figure 1 depicts the relationship between the four categories of explanatory theory we have distinguished.

\section{Conclusion}

We should abandon the tripartite classification and approach the philosophical topic of welfare with many more than three categories in mind. We should distinguish enumerative claims from explanatory claims, treating them for typological purposes as independent kinds of issue (though explanatory theories must of course be oriented to particular enumerations).

I have suggested that we should distinguish four categories of answer to each question. Treating the two questions as independent, we should recognise at least sixteen possible combinations of answers. This does not imply, of course, that there are exactly sixteen good candidate combined theories of welfare. Some of the possible combinations might be unappealing for various reasons. As I have mentioned, it could also be that finer-grained distinctions between views occupying the various categories I have specified are warranted in some cases. The sixteen categories are supposed to establish bearings and prompt consideration of possible combinations, not to replace detailed argument about the merits of particular theses. The main point is twofold: first, we should be careful to respect Crisp's 
According to the theory, is there a true informative answer to the

explanatory question?

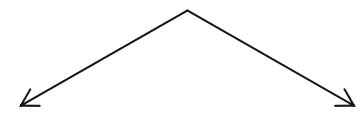

No

No-answer theories

\section{Yes}

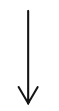

Does the explanation refer only to the subject's attitudes?

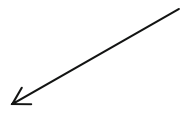

No

Yes

Subjective theories

Does the explanation refer to objective values?

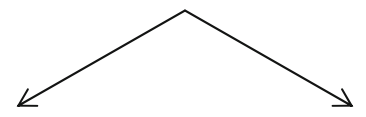

No

Yes

Naturalist theories Objective theories

Fig. 1 Proposed classification of explanatory theories

distinction-even if we believe that certain combinations of explanatory and enumerative view are incoherent; and second, we should think in terms of a much richer range of possible theories of welfare than is suggested by the tripartite classification.

Respecting Crisp's distinction may help to make various kinds of hybrid view seem more attractive. In particular, if we distinguish the explanatory and enumerative questions clearly we may be more inclined to take seriously enumerative theories that combine different requirements, such as the conjunctive and disjunctive enumerative hybrids briefly discussed in Sect. 2. For example, failure to distinguish the enumerative and explanatory questions can make it seem that, insofar as we believe that some pleasures are constituents of welfare, we must believe that all pleasures are, on pain of some kind of incoherence. But this is plainly not true. All sorts of enumerative hedges, combinations, and restrictions are possible. It of course remains a further question whether some satisfactory 
explanatory theory can be combined with the resulting enumerative theory-but the main point is that this is, indeed, a further question.

To illustrate this point, consider Mill's idea that higher quality pleasures have greater value than lower quality pleasures. This idea has been accused of incoherence or of abandoning hedonism (Mill 1991, pp. 138-139; Moore 1993, pp. 129-132). The accusation is incorrect if we characterise hedonism as I did above: qualitative hedonism endorses the experience requirement and identifies pleasure as the relevant sort of experience, and so it is a hedonist view. It goes on to specify the constituents of welfare using further distinctions, but there need be nothing incoherent in an enumerative theory doing that. However, it is much less clear that a satisfactory subjective explanatory theory could support these further distinctions. Qualitative hedonists claim that higher quality pleasures have higher value whether or not the subject agrees. It's hard to see how this claim can be explained, as subjectivists wish to do, entirely in terms of the subject's attitudes.

So there may be a kind of incoherence here, but if so it lies in the combination of qualitative hedonism with explanatory subjectivism. It could be that those who allege that qualitative hedonism itself is incoherent have tacitly assumed that it must be paired with a subjective explanatory theory. In fact, though, qualitative hedonism is more naturally paired with an objective explanatory theory according to which different qualities of pleasure make different contributions to welfare because pleasures of these kinds have correspondingly different amounts of objective value.

As this illustrates, one helpful effect of respecting Crisp's distinction is to refine criticisms of proposed theories of welfare: the complaint that some hybrid proposal is 'incoherent' should often be replaced by the complaint that it is explanatorily incomplete or in some other way unsatisfactory. In this and other ways, dispensing with the tripartite classification of theories of welfare may help us to make progress.

Acknowledgments I am grateful to Roger Crisp, Guy Fletcher, Carrie Ichikawa Jenkins, Daniel Nolan, Neil Sinclair, Jonathan Tallant, and several anonymous reviewers for comments on earlier drafts of this paper.

Open Access This article is distributed under the terms of the Creative Commons Attribution License which permits any use, distribution, and reproduction in any medium, provided the original author(s) and the source are credited.

\section{References}

Bailey, J. W. (1997). Utilitarianism, institutions, and justice. New York: Oxford University Press.

Brandt, R. B. (1979). A theory of the good and the right. Oxford: Clarendon Press.

Carson, T. L. (2000). Value and the good life. Notre Dame: University of Notre Dame Press.

Crisp, R. (2006). Reasons and the good. Oxford: Clarendon Press.

Crisp, R. (2008). Well-Being. Stanford Encyclopedia of Philosophy. Available at: http://plato.stanford. edu/entries/well-being. Accessed on September 12, 2011.

Darwall, S. (2002). Welfare and rational care. Princeton, NJ: Princeton University Press.

Feldman, F. (1997). Two questions about pleasure. In F. Feldman (Ed.), Utilitarianism, hedonism, and desert. Cambridge: Cambridge University Press.

Feldman, F. (2004). Pleasure and the good life. Oxford: Clarendon Press. 
Feldman, F. (2010). What is this thing called happiness? Oxford: Oxford University Press.

Fletcher, G. (2008). Good for. PhD Thesis, University of Reading, UK.

Fletcher, G. (2009). Rejecting well-being invariabilism. Philosophical Papers, 38, 21-34.

Fletcher, G. (forthcoming). A fresh start for objective-list theories of well-being. Utilitas.

Foot, P. (2001). Natural goodness. Oxford: Clarendon Press.

Griffin, J. (1986). Well-being: Its meaning, measurement, and moral importance. Oxford: Clarendon Press.

Hawkins, J. (2010). A new theory of well-being. Unpublished paper presented at the annual conference of the British Society for Ethical Theory, University of Nottingham, 9th July 2010.

Haybron, D. M. (2008). The pursuit of unhappiness. Oxford: Oxford University Press.

Heathwood, C. (2006). Desire satisfactionism and hedonism. Philosophical Studies, 128, 539-563.

Heathwood, C. (2010). Welfare. In J. Skorupski (Ed.), The Routledge companion to ethics (pp. 645-655). Abingdon: Routledge.

Kagan, S. (1998). Normative ethics. Boulder: Westview Press.

Kagan, S. (2009). Well-being as enjoying the good. Philosophical Perspectives, 23, 253-272.

Mill, J. S. (1991). Utilitarianism. In J. Gray (Ed.), On liberty and other essays. Oxford: Oxford University Press.

Moore, G. E. (1993). Principia Ethica. In T. Baldwin (Ed.), revised edition. Cambridge: Cambridge University Press.

Nozick, R. (1974). Anarchy, State, and Utopia. Oxford: Basil Blackwell.

Parfit, D. (1987). Reasons and persons, reprint with corrections. Oxford: Clarendon Press.

Scanlon, T. M. (1993). Value, desire, and quality of life. In M. Nussbaum \& A. Sen (Eds.), The quality of life (pp. 185-200). Oxford: Clarendon Press.

Scanlon, T. M. (1998). What we owe to each other. Cambridge, MA: Harvard University Press.

Sumner, L. W. (1996). Welfare, happiness, and ethics. Oxford: Clarendon Press. 